\title{
A simulation of earthquake induced undrained pore pressure changes with bearing on some soil liquefaction observations following the 2001 Bhuj earthquake
}

\author{
IREne SARKAR ${ }^{1}$ and RAMEsh ChandeR ${ }^{2}$ \\ ${ }^{1}$ Department of Earth Sciences, Indian Institute of Technology, Roorkee 247 667, India \\ ${ }^{2}$ House no. 290, Sector 4, Mansa Devi Complex, Panchkula 134 109, India
}

The Bhuj earthquake of January 26th, 2001, induced wide spread liquefaction within the Kachch peninsula. It has been pointed out that inundation due to soil liquefaction was short lived in some parts than in others in the affected region. Several geological, seismological and hydrological factors would have cumulatively contributed to these observed changes.

We simulate in this article, undrained or short-term change in pore pressure in a poroelastic half space, in response to a simplified model of the Bhuj earthquake source. We find that the regions of relatively shorter lived inundation due to soil liquefaction may fall in the region where pore pressure responsible for soil liquefaction attributable to strong ground shaking was counteracted by pore pressure changes due to undrained poroelastic effect and vice versa.

\section{Introduction}

The large magnitude $\left(M_{w}=7.7\right)$ Bhuj earthquake which occurred on January 26th, 2001, within the Kachch peninsula in Gujarat, was accompanied by wide spread liquefaction. Aerial and field surveys reported soil liquefaction and associated phenomena in the Great Rann, Little Rann, Banni Plains, Kandla River and Gulf of Kachch, between $69.75^{\circ} \mathrm{E}$ and $70.75^{\circ} \mathrm{E}$ at $23.97^{\circ} \mathrm{N},\left(71.45^{\circ} \mathrm{E}, 23.3^{\circ} \mathrm{N}\right)$, $\left(70.37^{\circ} \mathrm{E}, 22.72^{\circ} \mathrm{N}\right)$ and $\left(69.67^{\circ} \mathrm{E}, 23.5^{\circ} \mathrm{N}\right)$, covering an area of tens of thousands of kilometers (Hengesh and Lettis 2001).

Seismological literature includes numerous instances occurring worldwide (see for example Seed 1970) of similar coseismic effects of large and moderate earthquakes on the local hydrological regime. In the Indian context, in particular, the comprehensive reports of Oldham (1899) and Dunn (1939) on the damage induced by the great Indian earthquakes of 1897 and 1934 respectively are significant. These reports mention widespread incidence of intense soil liquefaction in the lower
Brahmaputra valley and north Bihar plains following the earthquakes.

In the case of both of these earthquakes, the reports of liquefaction are based only on field observations. But for the Bhuj earthquake case, along with field observations, satellite images of soil liquefaction and induced water surges, are also available. These pre- and post-earthquake remotesensing images of regions where such earthquake induced phenomena occurred help in systematic monitoring in real time of possible patterns in the ground water release. Clear recognition and investigations of such patterns should prove useful in the enhancement of our understanding of the seismological processes associated with the Bhuj earthquake.

Mohanty et al (2001) and Singh et al (2001) document incidence of soil liquefaction in parts of the Rann of Kachch during the 2001 Bhuj earthquake from remote sensing observations. From a comparison of satellite imageries taken three days after the Bhuj earthquake with the pre-earthquake imageries (figure 1) Mohanty et al (2001) have identified

Keywords. Undrained poroelastic effect, soil liquefaction, Bhuj earthquake. 


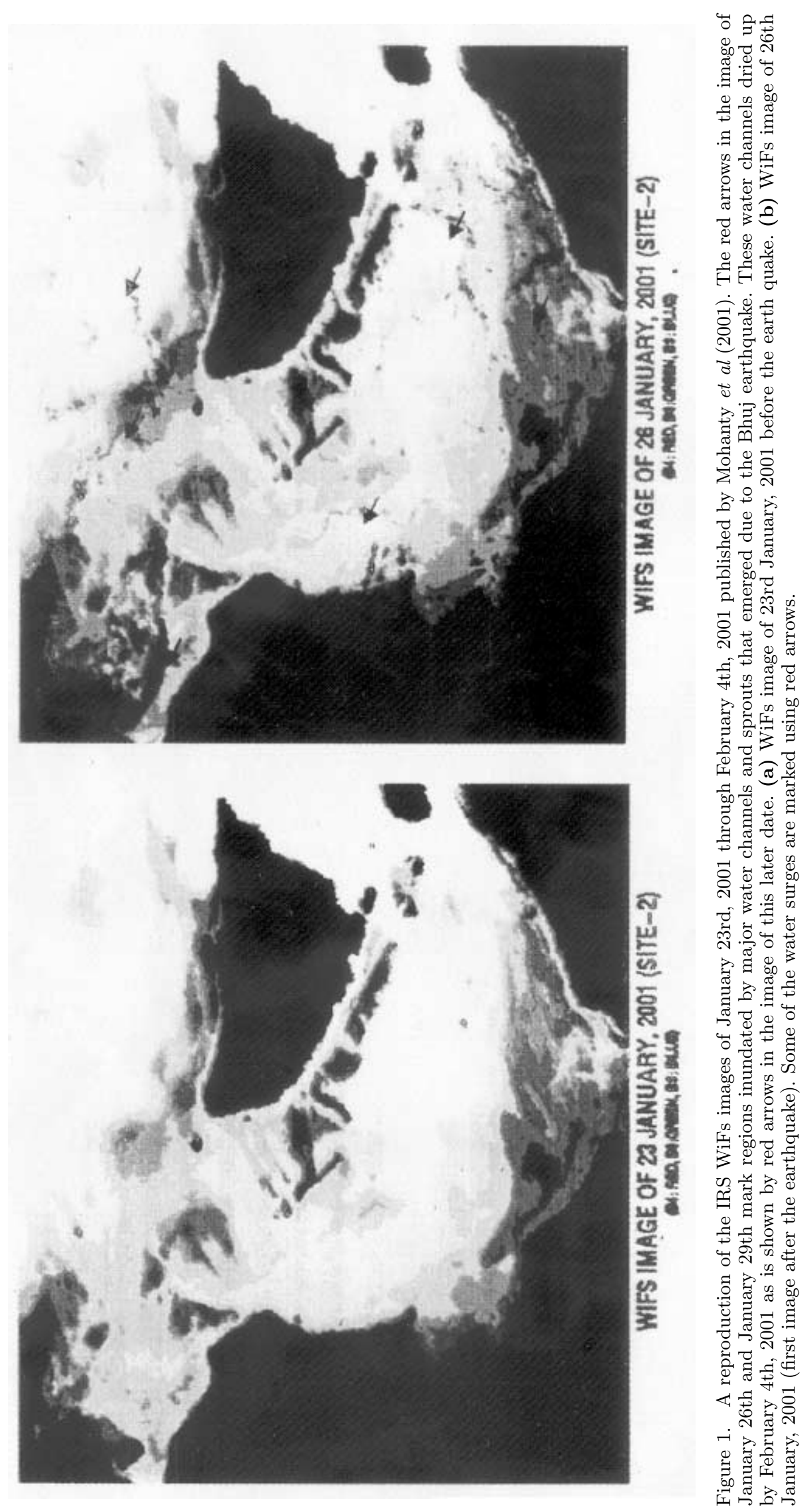




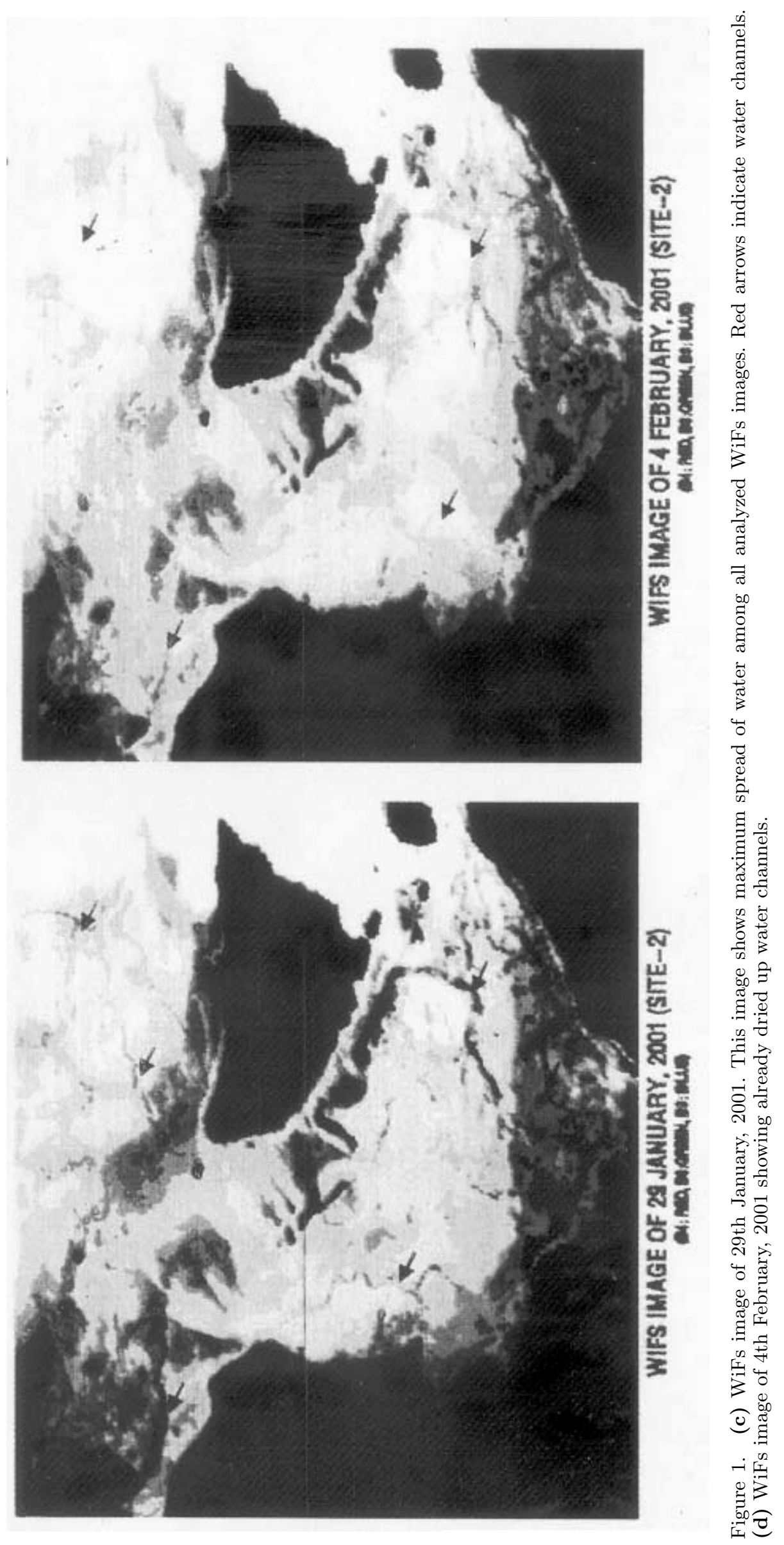


areas of pervasive inundation. They have also observed from the post-earthquake satellite imageries that over some areas these soil liquefaction effects were short lived. The imageries taken on February 4th, 2001, soon after the earthquake occurrence, show that the water had dried up at the surface over a large part of the inundated area (figure 1). In contrast, Singh et al (2001) observed that at Lodai village the inundation persisted even twelve to sixteen days after the earthquake. It thus transpires that while in some parts of Kachch area, the extruded water dried up very soon, it persisted for several days at others.

Different geological, seismological and hydrological factors could be responsible for these observations of the Bhuj earthquake-induced soil liquefaction effects. In this article we examine one possible factor viz., the short-term response of the shallow subsurface poroelastic rocks to the buried Bhuj earthquake dislocation.

\section{Method}

Our estimate of the short-term poroelastic effects induced by the Bhuj earthquake is based on the following considerations. The drying up phenomena were observed soon after the earthquake occurred i.e., during the period of short time response of the poroelastic earth to the earthquake-induced stresses, when the poroelastic subsurface rocks experienced undrained deformation. Since such type of deformation of a poroelastic medium is mathematically analogous to the elastic deformation of a linear isotropic medium, the undrained perturbations to the ambient pore pressure field, induced by the Bhuj earthquake immediately after its occurrence can be estimated in the manner explained below.

Several closed analytical expressions for internal and surficial displacement fields, due to different types of slip mechanisms on finite shear or tensile faults in a homogeneous, isotropic earth medium are available in literature (Mansinha and Smylie 1971; Ericson 1986; Okada, 1992 etc.). We use the theory of Mansinha and Smylie (1971) to estimate changes in the static elastic stress field in a solid half space, due to an earthquake source represented by a rectangular dip-slip rupture in the causative fault. The quasi-static poroelastic response $(\Delta p)$ can be estimated from the relation

$$
\Delta p=-B \Delta \sigma_{m}
$$

where $\Delta \sigma_{m}$ is the quasi-static perturbing mean stress field and $B$ is Skempton's coefficient.

For purpose of calculations, we assume the following rupture model for the Bhuj earthquake. (a) The causative fault has

- a dip of $45^{\circ}$ due south (Bodin et al 2001; Chiu et al 2001; Saikia et al 2001)

- is rectangular, with dimensions $35 \mathrm{~km}$ along and $40 \mathrm{~km}$ across the fault dip direction and

- terminates at a depth of $10 \mathrm{~km}$ below the ground surface.

(b) The hanging wall of the fault slipped uniformly by $5 \mathrm{~m}$ over the entire ruptured section in the direction of dip. We further assume that

(c) the epicentre is at $23.419^{\circ} \mathrm{N}, 70.232^{\circ} \mathrm{E}$, as per the revised estimates provided by US Geological Survey and

(d) that the shear modulus $(G)$, undrained Poisson's ratio $\left(\nu_{u}\right)$ and Skempton's coefficient $(B)$ have values $2.3 \times 10^{4} \mathrm{MPa}$ (Jaeger 1969), 0.25 and 0.5 (Detournay and Cheng 1993) respectively. The values of the fault rupture dimensions, fault slip and $G$ are together consistent (Aki and Richards 1980 ) with the seismic moment of $2.3 \times 10^{20} \mathrm{Nm}$ estimated by USGS for the Bhuj earthquake.

The estimated regions of increased and decreased pore pressure due to undrained behavior of poroelastic material located at a depth of $0.5 \mathrm{~km}$ in the earth medium in response to the Bhuj earthquake are demarcated in figure 2. In the figure, some of those localities where the inundation due to soil liquefaction had dried up by the ninth day have been identified. Note that these localities lie in the estimated region of decreased undrained pore pressure. Also shown in the figure is the site at Lodai, where inundation persisted even twelve to sixteen days after the earthquake. This lies in the estimated region of increased undrained pore pressure. We discuss the implications of these observations in the paragraphs below.

\section{Discussion}

We consider the role of induced pore pressure changes in the undrained state of deformation. Biot's (1941) quasi-static theory of poroelasticity suggests that after deformation of a water saturated poroelastic medium, changes in pore pressure may arise rapidly due to changes in elastic stresses and more slowly due to diffusion effects. The rapid pore pressure changes have been variedly refered to as pore pressure changes in the undrained state (Detournay and Cheng 1993) and also pore pressure changes due to compression (Rice and Cleary 1976). The time scale over which pore pressure changes due to liquefaction and undrained poroelastic behaviour may manifest themselves must depend on earth medium properties. However, the liquefaction related pore pressure changes due to earthquake induced ground vibrations may be expected to arise more rapidly 


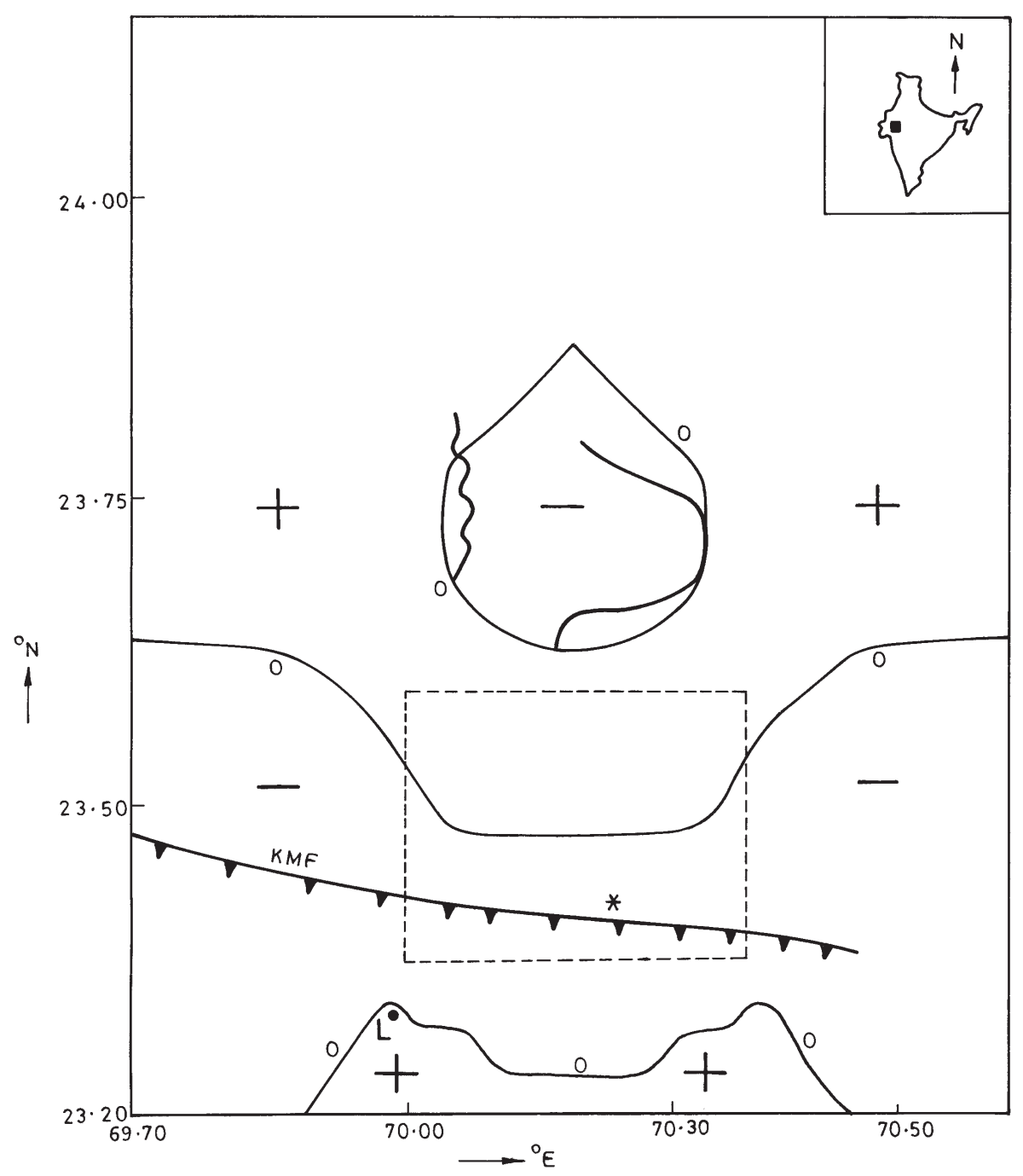

Figure 2. A map showing the estimated regions where pore pressure due to compression (see text) may have increased (plus signs) and decreased (minus signs) in response to undrained stress changes induced by the Bhuj earthquake. The pore pressure changes are estimated on a plane half a kilometre below and parallel to the surface of the poroelastic half space. Zero value contours (marked with 0s) separating regions of increased and decreased pore pressure on this plane are indicated. The projected position of the assumed causative rupture of the earthquake is represented by the dashed rectangle while the star marks the projected location of the Bhuj earthquake epicentre as estimated by US Geological Survey. The major water channels that appeared immediately after the earthquake but dried up within the ninth day, identified by two red arrows in the lower half of figure 1, lie in the zone of estimated reduced pore pressure. The other regions where inundated fields dried up by 4th February, as identified by red arrows in the upper regions of figure 1 fall outside the range of figure 2. The solid circle identified by $L$ in the zone of increased pore pressure is the projected position of Lodai village. The location of Kachch Mainland Fault (KMF) is adapted from Karanth (2001).

than pore pressure changes due to undrained poroelastic response of the medium after the earthquake.

Thus a possible implication of observing localities of short-lived inundation to lie in regions of decreased undrained pore pressure (figure 2) could be the following. Here the effect on water flow due to initial increase in pore pressure because of liquefaction has been overcome, at least partially, by the subsequent decrease in pore pressure because of undrained poroelastic behaviour. In contrast, at Lodai, which is located within a region of increased undrained pore pressure, the effect on water flow due to initial increase in pore pressure due to liquefaction has perhaps been further enhanced by the increase in pore pressure due to undrained poroelastic behaviour.

To assess the importance of our estimated pattern of quasi-static poroelastic response of the earth medium in the characteristic liquefaction effects observed in the Kachch peninsula after the Bhuj earthquake, we note the following.

Controlled laboratory experiments have confirmed that vibration can effectively compact cohesionless soils. When water saturated cohesionless 
soil is subjected to strong ground vibrations due to large earthquakes, the tendency to compact will be accompanied also by an increase in pore water pressure in the soil and result in an outward movement of water from the voids. Development of sufficiently high pore water pressures during large earthquake-induced ground vibrations can cause liquefaction of such water-saturated soils.

Several soil and water table related factors existing in the shallow surface control the sitedependent characteristics of such earthquakeinduced soil liquefaction processes. These include:

- the nature of the sediments, the grain size and intragranular packing (Seed 1970; Holzer 1989),

- regional topography (Seed 1970),

- nature and thickness of the cap rock,

- earthquake hypocentral distance (Papadopoulos and Lefkopoulos 1993),

- depth of the water table (Seed 1970; Roeloffs 1998 etc.),

- degree of water saturation of the soil (Seed 1970; Roeloffs 1998 etc.), and

- earthquake-induced changes in the pore water pressure (Ishihara et al 1981).

Thus the effects of seismic vibrations can be amplified in regions where there is

- abrupt topographic relief,

- shallow water table or,

- well sealed clayey soil overlying thick liquefiable sediments and cause the released water to persist on the earth surface for several days after the main shock.

Occurrence of large aftershocks in the region can further influence the flow of water. In contrast, in regions where the amount of ejected sand is far more than the amount of ejected water, the flow may cease within a few hours of the earthquake (see for example Seed 1970).

We are not in a position to assess the overall significance of poroelastic effects relative to other pore pressure generating or influencing factors. But our calculations suggest though that spatial variation of undrained pore pressure changes are in the same sense relative to soil liquefaction pore pressure as would help explain the observations under consideration logically.

\section{Conclusion}

For a detailed understanding of the site-specific characteristics of soil liquefaction that were observed during the Bhuj earthquake several factors related to near surface conditions of the soil and water table need to be considered. Our study based on estimates of the short term pore pressure changes induced by the earthquake suggest that the quasi-static poroelastic response of the underlying rocks of the region may also have a role in these observed patterns.

\section{Acknowledgement}

We are grateful to Mr. Ravi Gupta, Editor, GIS @ Development, for permitting us to reproduce figure 1 from Ref. 14.

\section{References}

Aki K and Richards P G 1980 Quantitative Seismology, V.1. Freeman, San Francisco, pp. 557

Biot M A 1941 General theory of three dimensional consolidation; J. Appl. Phys. 12 155-164

Bodin P, Horton S, Johnston A C, Withers M, Langston C A, Chiu J M, Budhbatti K and Gomberg J 2001 Aftershocks of the Gujarat, India, Republic Day earthquake; Seis. Soc. Amer. (Abstracts Online)

Chiu J M, Pujol J, Chiu S C, Withers W, Horton S, Bodin P, Johnston A C, Rydelek P, Bollwerk J and Patterson G 2001 Preliminary analysis of aftershock data from the January 26, 2001, India, "Republic Day" earthquake; Seis. Soc. Amer. (Abstracts Online)

Detournay E and Cheng A H -D 1993 In: Comprehensive Rock Engineering, V.2. (ed. C Fairhurst), (Oxford: Pergamon Press) pp. 113-171

Dunn J A, Auden J B, Ghosh A M N, Roy S C and Wadia D N 1939 The Bihar-Nepal earthquake of 1934; Mem. Geol. Surv. India $\mathbf{3 7}$

Ericson L 1986 A three-dimensional dislocation program with applications to faulting in the earth; M.S. thesis Stanford University, Stanford, California, pp. 167

Hengesh J V and Lettis W R 2001 Liquefaction and related effects from the $M_{w} 7.7$ Republic Day earthquake, India; Seis. Soc. Amer. (Abstracts Online)

Holzer T L 1989 Dynamics of liquefaction during the 1987 Superstition Hills, California, earthquake; Science $\mathbf{2 4 4}$ 56-59

Ishihara K, Shimuzu K and Yamada Y 1981 Pore water pressures measured in sand deposits during an earthquake; Soils Found. 21 85-100

Jaeger J C 1969 Elasticity, Fracture and Flow, (London: Methuen and Co. Ltd.) pp. 268

Karanth R V 2001 Structure and tectonics of the Kachchh region; GIS @ development 5 18-23

Mansinha L and Smylie D 1971 The displacement fields of inclined faults; Bull. Seis. Soc. Amer. 61 1433-1440

Mohanty K K, Maiti K and Nayak S 2001 Monitoring water surges; GIS @ development 5 32-33

Oldham R D 1899 Report on the great earthquake of 12 June, 1897; Mem. Geol. Surv. India 29, 1-379

Papadopoulos G A and Lefkopoulos G 1993 Magnitudedistance relations for liquefaction in soil from earthquakes; Bull. Seis. Soc. Amer. 83 925-938

Rice J R and Cleary M P 1976 Some basic stress diffusion solutions for fluid saturated elastic porous media with compressible constituents; Rev. Geophy. Space Phy. 14 $227-241$

Roeloffs E A 1998 Persistent water level changes in a well near Parkfield, California, due to local and distant earthquakes; J. Geophys. Res. 103 869-889 
Saikia C, Somerville P G, Ichinose G, Thio H K, Rao K S and Polet J 2001 Source parameters of the January 26th, 2001, Bhuj earthquake; Seis. Soc. Amer. (Abstracts Online)

Seed H B 1970 Soil Problems and Soil Behavior, In: Earthquake Engineering, (ed. R L Wiegel), Prentice Hall Inc., Englewood Cliffs, N.J., pp. 227-251
Singh R P, Bhoi S, Chandresh Sahoo A K and Kanwar R 2001 Changes in Ocean; GIS @ development 5 $35-36$

Website: http://home.iitk.ac.in/ ramesh/gujrat/gurajat.htm. Okada Y 1992 Internal deformation due to shear and tensile faults in a half space; Bull. Seis. Soc. Amer. 82 10181040 